\title{
Born to be asocial: newly hatched tortoises avoid unfamiliar individuals
}

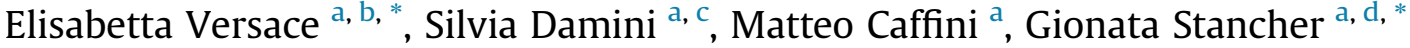 \\ a Center for Mind/Brain Sciences, University of Trento, Rovereto, Italy \\ ${ }^{\mathrm{b}}$ Department of Biological and Experimental Psychology, School of Biological and Chemical Sciences, Queen Mary University of London, London, U.K.

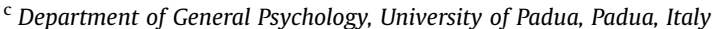 \\ ${ }^{\mathrm{d}}$ Rovereto Civic Museum Foundation, Rovereto, Italy
}

\section{A R T I C L E I N F O}

\section{Article history:}

Received 17 July 2017

Initial acceptance 17 October 2017

Final acceptance 12 January 2018

Available online $\mathrm{xxx}$

MS. number 17-00580R

\section{Keywords:}

hatchlings

individual recognition

predispositions

recognition of familiarity

social behaviour

tortoises
Recognition of familiar individuals is important for modulating social interactions, but it is not clear to what extent this capacity depends on experience gained through repeated interactions with different animals. In wild tortoises, evidence of social interactions is limited to behaviours performed years after hatching, in the context of mating. To investigate the capacity to recognize familiar individuals at the onset of life in tortoises, we used hatchlings of two species (Testudo marginata, Testudo graeca) reared with a single conspecific as their unique social experience. When in a novel environment with the familiar conspecific, tortoises reached the distance expected after running random trajectories. In contrast, tortoises tested with an unfamiliar conspecific first explored the other tested individual, then actively kept a distance from it significantly larger than expected by chance. These results show evidence of spontaneous recognition of familiar individuals in a nonsocial species at the onset of life, and active avoidance of unfamiliar conspecifics. We suggest that this predisposition might be adaptive for young tortoises' dispersal and that evolutionary pressures for social behaviour might be relevant for nonsocial species even at the onset of life.

(C) 2018 The Association for the Study of Animal Behaviour. Published by Elsevier Ltd. All rights reserved.
Recognition of familiar individuals and individual recognition require an animal to identify the features of organisms experienced in the past. These capacities are important for determining social responses in long-term social contexts (reviewed in Dale, Lank, \& Reeve, 2001; Tibbetts \& Dale, 2007): they can induce a closer relationship to mates and kin, modify responsiveness and aggression to neighbours compared to strangers and, in dominance hierarchies, trigger differential responses depending on the relationship with the identified individual. Precocial avian species provide evidence of familiar and individual recognition at the onset of life, since newly hatched birds are adapted to recognize and follow social partners after a brief exposure, through the mechanism of filial imprinting (Bateson, 1966; Bolhuis, 1991; Vallortigara \& Andrew, 1994; Zajonc, Wilson, \& Rajecki, 1975). It

\footnotetext{
* Correspondence: E. Versace, Department of Biological and Experimental Psychology, School of Biological and Chemical Sciences, Queen Mary University of London, Mile End Road, London E1 4NS, U.K.; G. Stancher, Fondazione Museo Civico Rovereto, Borgo Santa Caterina 41, 38068 Rovereto TN, Italy.

E-mail addresses: e.versace@qmul.ac.uk (E. Versace), stanchergionata@ fondazionemcr.it (G. Stancher).
}

is not clear whether, besides filial imprinting, recognition of familiar individuals is available at the onset of life, and whether this capacity is present in species with limited social habits.

We addressed these issues by investigating the behaviour of newly hatched tortoises, precocial animals that are known to be nonsocial. Tortoises do not exhibit posthatching parental care, they mate promiscuously and they do not form pair bonds or cohesive social groups (Ernst \& Barbour, 1989; Pearse \& Avise, 2001). In wild tortoises, evidence of social interactions is limited to behaviours that are performed when sexual maturity is reached, years after hatching, such as courtship, mounting and nesting (Auffenberg, 1977; Galeotti, Sacchi, Rosa, \& Fasola, 2005; Sacchi, Galeotti, Fasola, \& Ballasina, 2003; see for instance ; Swingland \& Stubbs, 1985). In captivity, tortoises housed with conspecifics show a capacity to follow the gaze of conspecifics (Wilkinson, Mandl, Bugnyar, \& Huber, 2010) irrespective of familiarity with them, and to learn from the actions of other individuals (Wilkinson, Kuenstner, Mueller, \& Huber, 2010), suggesting that these animals possess capacities to respond appropriately to social partners. It is not clear, though, whether these capacities emerge in captivity as a result of repeated social interactions or constitute the spontaneous behavioural repertoire of tortoises. Moreover, it is not 
clear whether tortoises are capable of recognizing familiar individuals and if this capacity is present at the onset of life.

To investigate whether tortoises can spontaneously recognize familiar individuals, we used hatchlings of two tortoise species (Testudo marginata, Testudo graeca). Tortoises were hatched in individual compartments and raised with a single conspecific as a unique social experience, before being tested in a novel environment with a familiar tortoise (familiar condition) or an unfamiliar tortoise (stranger condition). We expected to observe different responses to familiar and unfamiliar individuals only if tortoises were capable of recognizing familiar individuals. By using a circumscribed arena, we were able to compare the average distance between tortoises with that expected with random trajectories and to evaluate whether tortoises stayed closer to or further from each other in the familiar and stranger condition.

\section{METHODS}

\section{Subjects and Rearing Conditions}

We observed 26 newly hatched tortoises: $14 T$. graeca and 12 T. marginata individuals. Tortoises were about 1 month old (24-43 days of age, average 27 days) at the time of testing. Eggs laid on the ground by tortoises at the field station SperimentArea (Rovereto) were collected and incubated in darkness at $31 \pm 2{ }^{\circ} \mathrm{C}$. Tortoises hatched in individual compartments $(3 \times 4 \mathrm{~cm})$ and were then moved to individual boxes $(15 \times 15 \mathrm{~cm})$, with soil, leaves and straw covering the bottom, located outdoors (protected under a roof but exposed to daylight and partial shade). They were fed with green leaves ad libitum and gently hydrated with a spray watering can at least twice daily; this was sufficient to keep them well hydrated. The tortoises did not see any conspecific for about 10 days (2-20 days, average 10 days) before being paired with a tortoise of the same species. At this stage, each pair was housed in a square arena $(20 \times 20 \mathrm{~cm}$ and $12 \mathrm{~cm}$ high) with the bottom covered with soil, leaves and straw and maintained on the same regime as previously. Before the test, subjects did not see any other tortoise and did not interact with the experimenters.

\section{Experimental Apparatus}

As the experimental apparatus, we used a circular arena $(25 \mathrm{~cm}$ in diameter and $10 \mathrm{~cm}$ high; Fig. 1a) with the bottom covered with wet sand $(0.5 \mathrm{~cm})$. A Windows LifeCam camera hung above the centre of the arena recorded the tortoises' behaviour.

\section{Procedure}

We first familiarized tortoises with a conspecific by keeping a pair in the same enclosure for about 22 days (17-33 days, average 22.5 days). Tortoises were then tested in pairs of the same species (half of the pairs had the same mother, half had a different mother). Each tortoise was tested once or twice. The list of experimental pairs is shown in Table 1.

Before the beginning of the experimental session, we regulated the external temperature of the subjects by moving their box under a light, to make sure the temperature measured on the tops of the carapaces of the two tortoises differed by less than $2^{\circ} \mathrm{C}$. We measured the carapace temperature with an infrared thermometer. The average temperature of the pairs was $34.15^{\circ} \mathrm{C}$ in the Familiar condition and $34.09{ }^{\circ} \mathrm{C}$ in the Stranger condition.

Immediately before the test, each individual was isolated for $5 \mathrm{~min}$ in an opaque box. Subsequently, the experimental subjects were placed in front of each other (a familiar or a stranger tortoise, according to the experimental condition), facing the centre of the arena, at diametrically opposed positions (the furthest possible distance within the arena). The Supplementary video shows an example of the experimental procedure.

The behaviour was recorded for $15 \mathrm{~min}$ from the moment when one of the two tortoises made the first step. We defined as the first step a movement of at least one leg that displaced the carapace. If neither tortoise moved within $10 \mathrm{~min}$, the session was aborted and repeated the next day. To score the behaviour of tortoises, we extracted one frame every $20 \mathrm{~s}$ ( 3 frames/min) and used Image (Rasband, 2017) to identify the location of the centre of the carapace and the tip of the head of each tortoise in all frames.

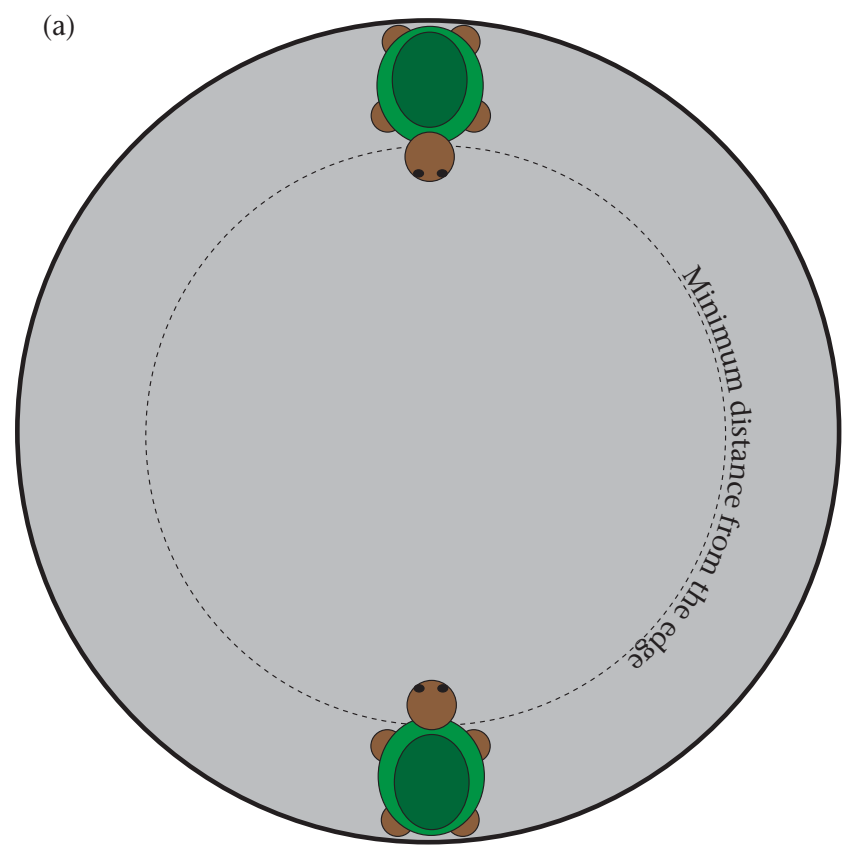

(b)

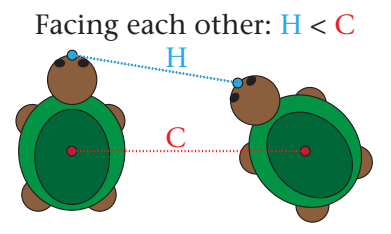

Facing the same direction, parallel: $\mathrm{H}=\mathrm{C}$

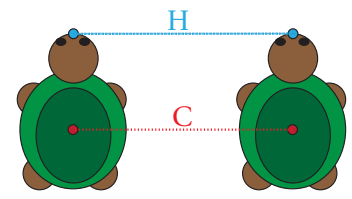

Facing away: $\mathrm{H}>\mathrm{C}$

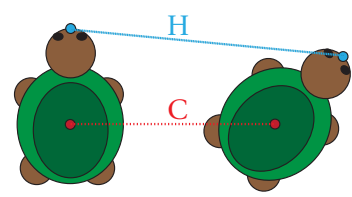

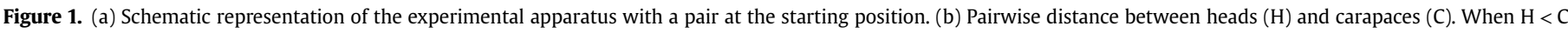
tortoises face each other, when $\mathrm{H}=\mathrm{C}$ tortoises are parallel, facing the same direction, and when $\mathrm{H}>\mathrm{C}$ tortoises face away from each other. 
Table 1

List of experimental pairs by species and condition

\begin{tabular}{lll}
\hline Species & Condition & Pair \\
\hline T. graeca & Familiar & $15-16$ \\
T. graeca & Familiar & $17-21$ \\
T. graeca & Stranger & $11-13$ \\
T. graeca & Stranger & $12-14$ \\
T. graeca & Stranger & $23-31$ \\
T. graeca & Stranger & $25-42$ \\
T. graeca & Stranger & $37-24$ \\
T. marginata & Familiar & $22-28$ \\
T. marginata & Familiar & $3-4$ \\
T. marginata & Familiar & $5-6$ \\
T. marginata & Familiar & $7-8$ \\
T. marginata & Stranger & $1-10$ \\
T. marginata & Stranger & $9-2$ \\
T. graeca & Familiar & $11-12$ \\
T. graeca & Familiar & $13-14$ \\
T. graeca & Familiar & $23-24$ \\
T. graeca & Familiar & $25-31$ \\
T. graeca & Familiar & $37-42$ \\
T. graeca & Stranger & $16-17$ \\
T. marginata & Familiar & $1-2$ \\
T. marginata & Familiar & $9-10$ \\
T. marginata & Stranger & $3-6$ \\
T. marginata & Stranger & $5-8$ \\
T. marginata & Stranger & $7-4$ \\
\hline
\end{tabular}

For each pair we calculated, for five consecutive periods of $3 \mathrm{~min}$ (15 min overall), the distances $(\mathrm{cm})$ between the centroids of the carapaces $(\mathrm{C})$ and between the tips of the heads $(\mathrm{H})$ and the difference between these measures $(\mathrm{H}-\mathrm{C})$. The distance between centroids of the carapaces provided an index of proximity irrespective of the relative orientation of the tortoises. The difference between the distance of the centroids and the distance of the heads provided an index of the relative orientation of the subjects: negative values indicate that tortoises are facing each other, positive values that tortoises are facing away from each other (see Fig. 1b).

\section{Identification of the Distance Expected with Random Trajectories}

To calculate the chance pairwise distance between tortoise centroids (carapace centroid) and between tortoise heads (tip of the head) we implemented a Fermi-like estimation method. Tortoises were simulated as circles with radius $1.82 \mathrm{~cm}$ with a circular head of radius $0.5 \mathrm{~cm}$. To obtain the chance carapace distance, we simulated the random positions of $2.5 \times 10^{7}$ pairs of tortoises uniformly distributed within an arena of radius $12.5 \mathrm{~cm}$ (the same size used in the experiments) and calculated their Euclidean pairwise distances. For the chance head distance, we first simulated the position of the carapace centroid, then simulated a random orientation of the head across $360^{\circ}$ around the centroid, and finally moved $1 \mathrm{~cm}$ away from the edge of the carapace. To avoid overlaps between individuals, we excluded pairs closer than twice the radius of an average tortoise (carapace). To exclude overlaps with the edge of the arena, we excluded positions of individuals closer to the edge than the radius of the tortoise.

We repeated the simulation 20 times and obtained a chance carapace distance of $10.47 \mathrm{~cm}$ and a chance head distance that converged to $10.85 \mathrm{~cm}$. All simulations were run with a custom MATLAB code that is available in the Supplementary material.

\section{Data Analysis}

We investigated the relationship between the dependent variables (Distance run, Distance between centroids, Distance between heads, Facing orientation) and the independent variables Condition (familiar versus stranger), Species ( $T$. marginata, T. graeca) and Time (1-3, 4-6, 7-9, 10-12, 13-15 min) as fixed effects and Pair as a random effect. Initially, we included the full set of explanatory variables and interactions and progressively found the minimum adequate model using $F$ tests for models fitted using maximum likelihood. For the variables Distance between centroids and Distance between heads, which showed a significant interaction between Condition and Time, we ran post hoc analyses of variance for the first and second half of the test separately. We used one-sample $t$ tests against the chance level obtained in the simulation to check for significant departures of the distance between centroids and of the distance between heads, independent $t$ tests to compare distance between conditions at specific time points and paired $t$ tests to compare distance within condition between two time points. Significance was set at $P<0.05$.

For the Familiar and Stranger conditions, we identified the bestfit trend of each dependent variable (Distance between centroids, Distance between heads, Facing orientation) in Time using a polynomial regression with increasing complexity, from linear to fourth level polynomial, and used the maximum likelihood method to compare models. We accepted as best-fit the most parsimonious model that provided a significant increase of fit.

To investigate the effect of kinship, we checked whether pairs with the same or a different mother differed in the distance between centroids, distance between heads, facing orientation and distance run using an ANOVA on each dependent variable, with Kinship (same versus different mother), Condition and Time as independent variables.

The supporting data set is available in the Supplementary material. Analyses were conducted with $\mathrm{R}$ (version 3.2.1, The $\mathrm{R}$ Foundation for Statistical Computing, Vienna, Austria, http://www. r-project.org).

\section{Ethical Note}

After the experiments, the tortoises were released on the ground in protected areas at SperimentaArea. The experimental procedures were approved by the Ethical Committee of the Fondazione Museo Civico Rovereto (Italy). Experiments comply with the current Italian and European Union laws for the ethical treatment of animals and are in line with the ASAB/ABS Guidelines for the Use of Animals in Research.

\section{RESULTS}

\section{Distance Between Centroids}

Distance between carapace centroids of the tortoises was analysed with Condition, Species and Time as fixed effects and Pair as random effect, using a linear mixed-effect model fitted using maximum likelihood. The minimum adequate model included Condition $\left(F_{1,22}=0.444, P=0.512\right)$, Time $\left(F_{4,88}=7.694, P<0.0001\right)$ and Condition $*$ Time $\left(F_{4,88}=3.003, P=0.023\right.$; Fig. $\left.2 a\right)$. There was no significant effect or interaction of the Species factor. As post hoc tests, we ran one analysis of variance for the first and one for the last half of the experiment, using Condition as between factor and Time as within factor. In the first part of the experiment there was no significant main effect of Condition $\left(F_{1,22}=0.411, P=0.528\right)$, a significant main effect of Time $\left(F_{2,44}=7.50, P=0.002\right)$ and no significant interaction $\left(F_{2,44}=1.559, P=0.222\right)$. In the second half there was no significant main effect (Condition: $F_{1,22}=2.967$, $P=0.100$; Time: $F_{2,44}=1.730, P=0.189$ ) but a significant interaction Condition $*$ Time $\left(F_{2,44}=3.613, \quad P=0.035\right)$. While in the 

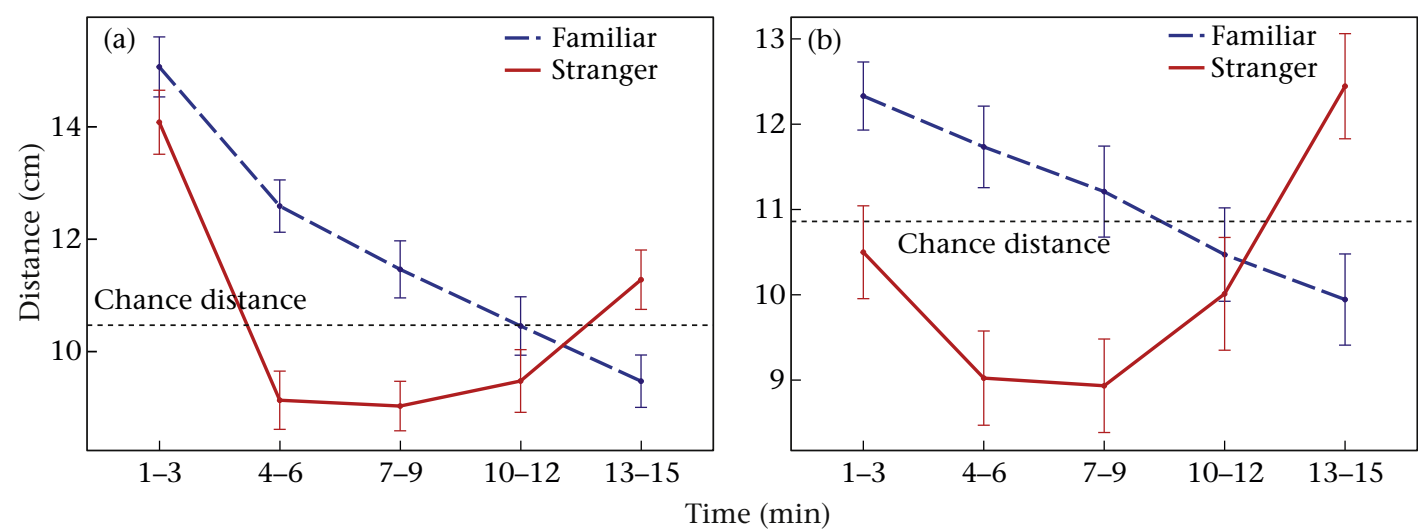

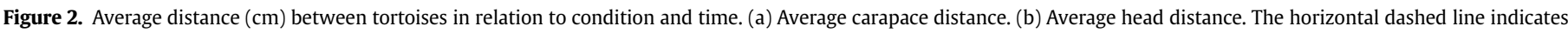
the chance distance calculated with Fermi-like simulations.

Familiar condition tortoises progressively approached the chance level distance, in the Stranger condition tortoises initially approached the other subject and then moved significantly further than the chance distance (one-sample $t$ test: $t_{10}=2.77, P=0.020$; paired $t$ test: $t_{10}=1.659, P=0.128$ ). In all time points and conditions, carapace pairs were significantly closer than the average starting distance $(20.74 \mathrm{~cm})$. The best-fit model for the Familiar condition was linear $(F=70.89, P<0.001)$, while for the Stranger condition it was cubic $(F=21.86, P<0.001)$.

\section{Distance Between Heads}

The minimum adequate model included Time as the only significant main effect $\left(F_{4,92}=3.428, P=0.015\right)$, while Condition and Species were not significant as main effects or in interaction (Fig. 2b). As post hoc tests, we ran one analysis of variance for the first and one for the last half of the experiment, using Condition as between factor and Time as within factor. In the first part of the experiment there was no significant main effect of Condition $\left(F_{1,22}=1.730, P=0.202\right)$ or Time $\left(F_{2,44}=0.712, P=0.49\right)$ and no significant interaction $\left(F_{2,44}=0.201, P=0.819\right)$. In the second half of the experiment there was no significant main effect (Condition: $F_{1,22}=2.485, P<0.001$; Time: $\left.F_{2,44}=0.702, P=0.501\right)$ but a significant interaction Condition $*$ Time $\left(F_{2,44}=4.267, P=0.020\right)$. While in the Familiar condition tortoises progressively approached the chance level distance, in the Stranger condition tortoises initially approached the other subject and then moved significantly further than the chance distance (one-sample $t$ test: $t_{10}=3.704, P=$ 0.004; paired $t$ test: $t_{10}=2.679, P=0.023$; Table 2 ). In all time points and conditions, head pairs were significantly closer than the average starting distance $(14.87 \mathrm{~cm})$. The best-fit model for the Familiar condition was linear $(F=14.51, P<0.001)$, while for the Stranger condition it was quadratic $(F=11.91, P<0.001)$.

\section{Facing Orientation}

Overall, we found no significant effects or interactions. However, limiting the analysis to the first two time points, in which tortoises started to move from the starting position and orientation, we observed a significant effect of Time $\left(F_{1,22}=16.22, P<0.001\right)$, no significant effect of Condition $\left(F_{1,22}=1.436, P=0.24\right)$ and a significant interaction Condition $*$ Time $\left(F_{1,22}=5.521, P=0.028\right.$; Fig. 3$)$. As shown by one-sample $t$ tests against the chance level (0), the propensity to face each other changed during the test: at time point 1-3 min, tortoises in both conditions exhibited a significant preference to face each other (Familiar: $t_{12}=-5.146, P<0.001$;
Stranger: $t_{10}=-8.858, P<0.001$ ), while at time point $12-15 \mathrm{~min}$ tortoises in the Stranger condition had a significant preference to face in different directions $\left(t_{12}=3.363, P=0.007\right)$ while tortoises in the Familiar condition did not $\left(t_{10}=1.077, P=0.303\right)$. These effects suggest tortoises in the Stranger condition initially oriented more towards the other individual than Familiar tortoises, while in the second part of the test they oriented less towards the other individual than Familiar tortoises. The best-fit model for the Familiar condition was quadratic $(F=41.38, P<0.001)$, while for the Stranger condition it was a fourth level polynomial $(F=43.77$, $P<0.001)$

\section{Distance Run}

The minimum adequate model included only Time $\left(F_{4,88}=3.46\right.$, $P=0.011)$ and Species $*$ Time $\left(F_{4,88}=2.27, P=0.068\right.$; Fig. 4$)$. The best-fit model was linear for both the Familiar condition $(F=6.66$, $P=0.010)$ and the Stranger condition $(F=5.922, P=0.015)$.

\section{Kinship}

Kinship was not significant as a main effect or in interaction with other variables (Table 3 ). These results strongly suggest that kinship, which is connected to olfactory and visual similarity between tortoises, did not affect the approach responses of tortoises.

\section{DISCUSSION}

Our results show evidence of spontaneous recognition of familiar individuals in tortoise hatchlings that had been previously

Table 2

Average distance between the heads of pairs of tortoises and the results of onesample $t$ tests against the chance carapace distance $(9.35 \mathrm{~cm})$ obtained by simulated data

\begin{tabular}{lllll}
\hline Condition & Time $(\mathrm{min})$ & Head distance $(\mathrm{cm})$ & $t$ & $P$ \\
\hline Familiar & $1-3$ & 12.33 & 3.890 & 0.002 \\
Familiar & $4-6$ & 11.73 & 2.36 & 0.036 \\
Familiar & $7-9$ & 11.21 & 1.670 & 0.115 \\
Familiar & $10-12$ & 10.47 & 1.047 & 0.316 \\
Familiar & $13-15$ & 9.849 & 0.498 & 0.627 \\
Stranger & $1-3$ & 10.50 & 1.134 & 0.283 \\
Stranger & $4-6$ & 9.023 & -0.268 & 0.794 \\
Stranger & $7-9$ & 8.93 & -0.418 & 0.684 \\
Stranger & $10-12$ & 10.01 & 0.553 & 0.592 \\
Stranger & $13-15$ & 12.44 & 3.261 & 0.009 \\
\hline
\end{tabular}




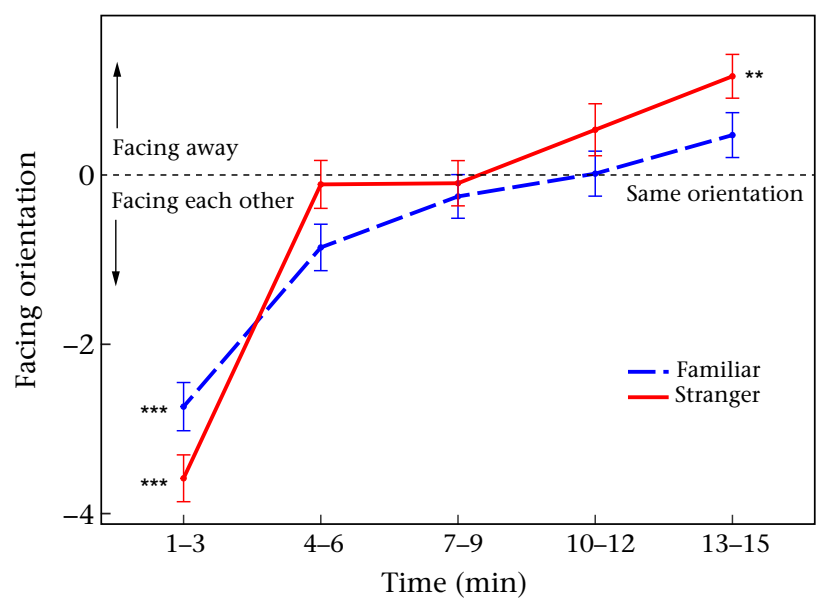

Figure 3. Facing orientation of tortoises in relation to condition and time. Negative values indicate tortoises facing each other; positive values the opposite orientation. The horizontal dashed line indicates the chance level calculated with Fermi-like simulations. Significance against the chance level (same orientation, facing in the same direction) is indicated by asterisks: ${ }^{* * *} P<0.001 ;{ }^{* *} P<0.01$

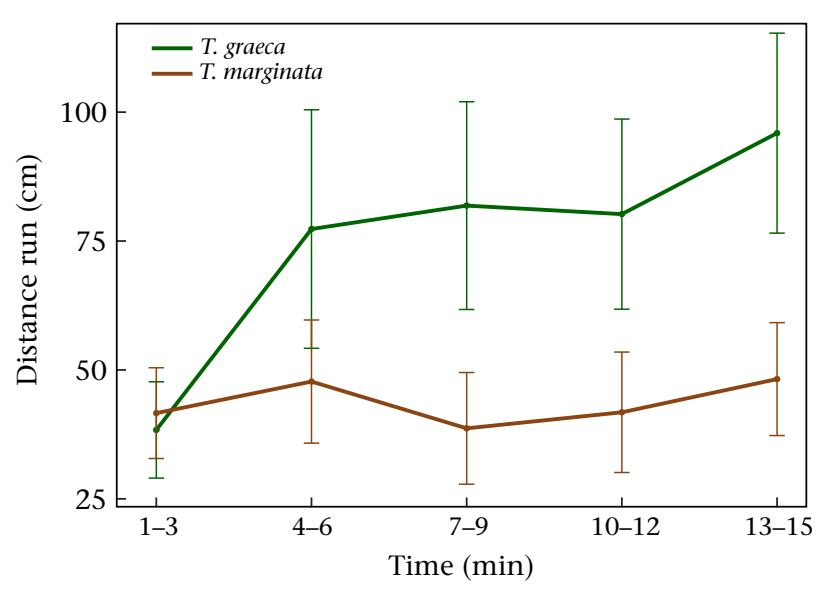

Figure 4. Distance run by each pair $(\mathrm{cm})$ in relation to species and time.

exposed to only one conspecific, and active avoidance of unfamiliar conspecifics. The capacity to recognize familiar and particular individuals has been mainly investigated in contexts of repeated interactions, such as kin recognition, neighbour-stranger recognition and dominance hierarchies (reviewed in Dale et al., 2001; Tibbetts \& Dale, 2007). Recognition of specific individuals has been documented in various taxa, such as fish (Miklosi, Haller, \& Csanyi, 1997; Myrberg \& Riggio, 1985), mammals (Brennan \& Kendrick, 2006; Johnston, 2003), reptiles (Husak \& Fox, 2003; Olsson, 1994), birds (Beer, 1971; Jouventin, Aubin, \& Lengagne, 1999; Whitfield, 1986; Wilkinson, Specht, \& Huber, 2010) and invertebrates (Karavanich \& Atema, 1998; Tibbetts, 2002). Since, in most studies, affiliative or competitive interactions occurred several times before recognition was tested, it is not clear to what extent individual recognition and recognition of familiar animals require an individual to have experience with multiple subjects. The case of filial imprinting in precocial avian species is a notable exception: through this learning mechanism, chicks of the domestic fowl promptly recognize familiar individuals after a single exposure (Bateson, 1966; Bolhuis, 1991; Vallortigara \& Andrew, 1994; Zajonc et al., 1975) and exhibit affiliative responses towards the imprinting stimulus. Chicks and other social species exhibit several predispositions for social behaviour soon after hatching ( $\mathrm{Di}$
Table 3

The effect of kinship, condition and time on the dependent variables

\begin{tabular}{lllll}
\hline Dependent variable & Effect & $F$ & $d f$ & $P$ \\
\hline Distance between centroids & Kinship & 0.470 & 1,19 & 0.501 \\
& Kinship*Condition & 4.414 & 1,19 & 0.080 \\
& Kinship*Time & 0.626 & 4,80 & 0.645 \\
& Kinship*Condition*Time & 0.390 & 4,80 & 0.815 \\
Distance between heads & Kinship & 0.143 & 1,19 & 0.710 \\
& Kinship*Condition & 2.616 & 1,19 & 0.122 \\
& Kinship*Time & 0.750 & 4,80 & 0.561 \\
Facing orientation & Kinship*Condition *Time: & 0.529 & 4,80 & 0.715 \\
& Kinship & 0.363 & 1,19 & 0.554 \\
& Kinship*Condition & 0.368 & 1,19 & 0.551 \\
& Kinship*Time & 1.017 & 4,80 & 0.404 \\
Distance run & Kinship*Condition *Time & 1.718 & 4,80 & 0.154 \\
& Kinship & 1.749 & 1,19 & 0.202 \\
& Kinship*Condition & 1.435 & 1,19 & 0.246 \\
& Kinship*Time & 1.020 & 4,80 & 0.402 \\
& Kinship*Condition *Time & 0.700 & 4,80 & 0.594 \\
\hline
\end{tabular}

Giorgio et al., 2016), and these behaviours have a genetic component (Versace, Fracasso, Baldan, Dalle Zotte, \& Vallortigara, 2017). It is not known, though, whether exposure to a single individual is sufficient to elicit recognition at the onset of life in other species, including nonsocial animals. Showing an ability to recognize familiar individuals in tortoise hatchlings would suggest a certain independence of this ability from complex social experience and the possibility that this trait has evolved in contexts other than repeated social interactions.

Here, we documented the first evidence of spontaneous recognition of familiar individuals in hatchlings of two species of tortoises (T. graeca and T. marginata) previously exposed to a single conspecific for a few days. In the wild, tortoises of this age are solitary. At test, tortoises were placed in a novel environment, so that no territoriality was present for the test arena. Tortoises of both species showed the same strikingly different behavioural responses in the two conditions. While pairs of familiar tortoises appeared to ignore each other in the chosen trajectories, and progressively reached the chance level distance, strangers initially approached each other much faster than familiar pairs, then walked away from each other and reached a significantly larger distance. Interestingly, in the first part of the test unfamiliar individuals approached each other faster than familiar individuals, suggesting an initial interest in the unfamiliar conspecific. This observation is supported by the fact that tortoises in the Stranger condition faced the other individual more than tortoises in the Familiar condition. The absence of locomotor differences between familiar and stranger pairs indicates the absence of spurious differences between conditions.

We hypothesize that the spontaneous avoidance of unfamiliar tortoise hatchlings might be an adaptation to help dispersal of the brood, and for this reason is conserved between species. The partial overlap of the habitats of these species and their close phylogenetic distance (Fritz \& Bininda-Emonds, 2007; Parham et al., 2006; van der Kuyl et al., 2002) suggest they might have similar social behaviours. In the wild, $T$. marginata and $T$. graeca are known to lay one to four clutches per year and each clutch contains three to seven eggs (Diaz-Paniagua, Keller, \& Andreu, 1997; Hailey and Loumbourdis, 1988) (in captivity, we observed larger clutches, up to 12 eggs per individual in T. marginata). Hence, without active dispersal hatchlings would quickly saturate the carrying capacity of the environment; moreover, without dispersal the entire clutch would be more exposed to predation. In line with this idea, the ranges of hatchlings show little overlap (Keller, Diaz-Paniagua, \& Andreu, 1997) and female T. graeca increase mobility before or after nesting, thus dispersing nests over a wide area (Diaz-Paniagua, 
Keller, \& Andreu, 1996). Overall, our results show that nonsocial species, such as land tortoises, possess the capacity to recognize familiar individuals at the onset of life, after very limited experience with other individuals. This suggests that the capacity for recognition might have evolved in contexts other than repeated social interactions, and that even in nonsocial species selection for social/ asocial behaviour is at work at the onset of life. The absence of effects of kinship on the recognition of familiar/stranger individuals strongly suggests that tortoise hatchlings use visual rather than olfactory cues for recognition. Further studies should investigate the exact sensory basis of recognition of familiar individuals in tortoise hatchlings.

\section{Conflicts of Interest}

We have no conflicts of interest.

\section{Authors' Contributions}

E.V. and G.S conceived the project; G.S., E.V. and S.D. designed the experiment; S.D. carried out the experiment; E.V. M.C. and S.D. analysed the data; M.C. developed the simulations; E.V. drafted the paper; all authors revised the manuscript and gave final approval for publication.

\section{Acknowledgments}

We thank the internship students of the high-school 'Liceo A. Rosmini' (Rovereto, Italy) for help in data collection, and the Rovereto Civic Museum Foundation, which provided the facilities to carry out this research. This research was supported by a European Research Council grant under the European Union's Seventh Framework Programme (FP7/2007-2013): Advanced Grant ERC PREMESOR G.A. Number 295517.

\section{Supplementary Material}

Supplementary material related to this article can be found at https://doi.org/10.1016/j.anbehav.2018.02.012.

\section{References}

Auffenberg, W. (1977). Display behavior in tortoises. American Zoologist, 17(1), 241-250. https://doi.org/10.1093/icb/17.1.241.

Bateson, P. (1966). The characteristics and context of imprinting. Biological Reviews of the Cambridge Philosophical Society, 41(2), 177-211. Retrieved from http:/ www.ncbi.nlm.nih.gov/pubmed/5295796.

Beer, C. G. (1971). Individual recognition of voice in the social behavior of birds. Advances in the Study of Behavior, 3, 27-74. https://doi.org/10.1016/S00653454(08)60154-0.

Bolhuis, J. J. (1991). Mechanisms of avian imprinting: A review. Biological Reviews, 66(4), 303-345. https://doi.org/10.1111/j.1469-185X.1991.tb01145.x.

Brennan, P. A., \& Kendrick, K. M. (2006). Mammalian social odours: Attraction and individual recognition. Philosophical Transactions of the Royal Society B: Biological Sciences, 361(1476), 2061-2078. https://doi.org/10.1098/rstb.2006.1931.

Dale, J., Lank, D. B., \& Reeve, H. K. (2001). Signaling individual identity versus quality: A model and case studies with ruffs, queleas, and house finches. The American Naturalist, 158(1), 75-86. https://doi.org/10.1086/320861.

Di Giorgio, E., Loveland, J., Mayer, U., Rosa-Salva, O., Versace, E., \& Vallortigara, G. (2016). Filial responses as predisposed and learned preferences: Early attachment in chicks and babies. Behavioural Brain Research, 325, 90-104.

Diaz-Paniagua, C., Keller, C., \& Andreu, a C. (1996). Clutch frequency, egg and clutch characteristics, and nesting activity of spur-thighed tortoises, Testudo graeca, in southwestern Spain. Canadian Journal of Zoology, 74, 560-564. https://doi.org/ 10.1139/z96-061. June 2014.

Diaz-Paniagua, C., Keller, C., \& Andreu, A. C. (1997). Hatching success, delay of emergence and hatchling biometry of Testudo graeca in Spain.pdf. Journal of Zoology, 243, 543-553.

Ernst, C. H., \& Barbour, R. W. (1989). Turtles of the world. Washington DC: Smithsonian Institution Press.
Fritz, U., \& Bininda-Emonds, O. R. P. (2007). When genes meet nomenclature: Tortoise phylogeny and the shifting generic concepts of Testudo and Geochelone. Zoology, 110(4), 298-307. https://doi.org/10.1016/j.zool.2007.02.003.

Galeotti, P., Sacchi, R., Rosa, D. P., \& Fasola, M. (2005). Female preference for fastrate, high-pitched calls in Hermann's tortoises Testudo hermanni. Behavioral Ecology, 16(1), 301-308. https://doi.org/10.1093/beheco/arh165.

Hailey, A., \& Loumbourdis, N. S. (1988). Egg size and shape, clutch dynamics, and reproductive effort in European tortoises. Canadian Journal of Zoology, 66(7) 1527-1536. https://doi.org/10.1139/z88-224.

Husak, J. F., \& Fox, S. F. (2003). Adult male collared lizards, Crotaphytus collaris increase aggression towards displaced neighbours. Animal Behaviour, 65(2) 391-396. https://doi.org/10.1006/anbe.2003.2058.

Johnston, R. E. (2003). Chemical communication in rodents: From pheromones to individual recognition. Journal of Mammalogy, 84(4), 1141-1162. https://doi.org/ 10.1644/BLe-010.

Jouventin, P., Aubin, T., \& Lengagne, T. (1999). Finding a parent in a king penguin colony: The acoustic system of individual recognition. Animal Behaviour, 57(6), 1175-1183. https://doi.org/10.1006/anbe.1999.1086.

Karavanich, C., \& Atema, J. (1998). Individual recognition and memory in lobster dominance. Animal Behaviour, 56(6), 1553-1560. https://doi.org/10.1006/ anbe.1998.0914.

Keller, C., Diaz-Paniagua, C., \& Andreu, A. C. (1997). Post-emergent field activity and growth rates of hatchling spur-thighed tortoises, Testudo graeca. Canadian Journal of Zoology-Revue Canadienne de Zoologie, 75(7), 1089-1098.

van der Kuyl, A. C., Ph Ballasina, D. L., Dekker, J. T., Maas, J., Willemsen, R. E., \& Goudsmit, J. (2002). Phylogenetic relationships among the species of the Genus Testudo (Testudines: Testudinidae) inferred from mitochondrial 12S rRNA gene sequences. Molecular Phylogenetics and Evolution, 22(2), 174-183. https:/| doi.org/10.1006/mpev.2001.1052.

Miklosi, A., Haller, J., \& Csanyi, V. (1997). Learning about the opponent during aggressive encounters in paradise fish (Macropodus opercularis L.): When it takes place? Behavioural Processes, 40(1), 97-105. https://doi.org/10.1016/ S0376-6357(96)00755-3.

Myrberg, A. A., \& Riggio, R. J. (1985). Acoustically mediated individual recognition by a coral reef fish (Pomacentrus partitus). Animal Behaviour, 33(2), 411-416. https://doi.org/10.1016/S0003-3472(85)80065-8.

Olsson, M. (1994). Rival recognition affects male contest behavior in sand lizards (Lacerta agilis). Behavioral Ecology and Sociobiology, 35, 249-252.

Parham, J. F., Macey, J. R., Papenfuss, T. J., Feldman, C. R., Türkozan, O., Polymeni, R. et al. (2006). The phylogeny of Mediterranean tortoises and their close relatives based on complete mitochondrial genome sequences from museum specimens. Molecular Phylogenetics and Evolution, 38(1), 50-64. https://doi.org/10.1016| j.ympev.2005.07.015.

Pearse, D. E., \& Avise, J. C. (2001). Turtle mating systems: Behavior, sperm storage, and genetic paternity. Journal of Heredity, 92(2), 206-211. https://doi.org/ 10.1093/jhered/92.2.206.

Rasband, W. (2017). ImageJ. Bethesda, MD: U.S. National Institutes of Health. http:/ imagej.nih.gov/ij/.

Sacchi, R., Galeotti, P., Fasola, M., \& Ballasina, D. (2003). Vocalizations and courtship intensity correlate with mounting success in marginated tortoises Testudo marginata. Behavioral Ecology and Sociobiology, 55, 95-102. https://doi.org/ 10.1007/s00265-003-0685-1.

Swingland, I. R., \& Stubbs, D. (1985). The ecology of a Mediterranean tortoise (Testudo hermanni): Reproduction. Journal of Zoology, London, 205(1 985), 595-610.

Tibbetts, E. A. (2002). Visual signals of individual identity in the wasp Polistes fuscatus. Proceedings of the Royal Society B: Biological Sciences, 269(1499), 1423-1428. https://doi.org/10.1098/rspb.2002.2031.

Tibbetts, E. A., \& Dale, J. (2007). Individual recognition: It is good to be different. Trends in Ecology \& Evolution, 22(10), 529-537. https://doi.org/10.1016/ j.tree.2007.09.001.

Vallortigara, G., \& Andrew, R. J. (1994). Differential involvement of right and left hemisphere in individual recognition in the domestic chick. Behavioural Processes, 33(1-2), 41-57. https://doi.org/10.1016/0376-6357(94)90059-0.

Versace, E., Fracasso, I., Baldan, G., Dalle Zotte, A., \& Vallortigara, G. (2017). Newborn chicks show inherited variability in early social predispositions for hen-like stimuli. Scientific Reports, 7, 40296. https://doi.org/10.1038/srep40296 (January).

Whitfield, D. P. (1986). Plumage variability and territoriality in breeding turnstone Arenaria interpres: Status signalling or individual recognition? Animal Behaviour 34(5), 1471-1482. https://doi.org/10.1016/S0003-3472(86)80218-4.

Wilkinson, A., Kuenstner, K., Mueller, J., \& Huber, L. (2010). Social learning in a nonsocial reptile (Geochelone carbonaria). Biology Letters, 6(5), 614-616. https:// doi.org/10.1098/rsbl.2010.0092.

Wilkinson, A., Mandl, I., Bugnyar, T., \& Huber, L. (2010). Gaze following in the redfooted tortoise (Geochelone carbonaria). Animal Cognition, 13(5), 765-769. https://doi.org/10.1007/s10071-010-0320-2.

Wilkinson, A., Specht, H. L., \& Huber, L. (2010). Pigeons can discriminate group mates from strangers using the concept of familiarity. Animal Behaviour, 80(1) 109-115. https://doi.org/10.1016/j.anbehav.2010.04.006.

Zajonc, R. B., Wilson, W. R., \& Rajecki, D. W. (1975). Affiliation and social discrimination produced by brief exposure in day-old domestic chicks. Animal Behaviour, 23(Part 1), 131-138. https://doi.org/10.1016/0003-3472(75)90059-7. 